\title{
Determining the Optimal Method of Allocating Credits and Granting Facilities in the Student Welfare Fund of Ministry of Health and Medical Education using Fuzzy AHP
}

\author{
Sara Emamgholipour Sefiddashti ${ }^{1}$, Mohammad Arab ${ }^{1}$, Majid Meshkini ${ }^{2}$, Soheil Mokhtari ${ }^{1^{*}}$
}

\author{
${ }^{1}$ Department of Health Management \& \\ Economic, School of Public Health, \\ Tehran University of Medical Sciences, \\ Tehran, IRAN \\ 2 Department of Epidemiology, School
of Public Health, Iran University of
Medical Sciences (IUMS), Tehran, IRAN \\ * Corresponding author: \\ so.1373@yahoo.com
}

\begin{abstract}
Introduction: Student support systems try to provide access to higher education for students from all socio-economic backgrounds, which is itself one of the main pillars of sustainable development. This study aims to identify the types of material and spiritual support of students in the world and to study the support institutions of students in the country while devising practical indicators for granting facilities to students and prioritizing these types of indicators using fuzzy analytical hierarchy process (FAHP) method to choose a model to provide this type of support as efficiently and effectively as possible and be able to establish justice in this type of support.

Research Method: The present study is descriptive-analytical in terms of purpose, practical in terms of results, library and survey research in terms of data collection method with a cross-sectional time horizon that includes qualitative and quantitative phases. First, by studying 18 developed countries due to access to information on official websites and relevant valid articles and booklets, as well as studying student support organizations in the country, basic information and complete knowledge of the issues of different groups of students and methods of addressing or meeting these needs were acquired. Then, in a working group discussion consisting of student facilities experts of the Student Welfare Fund, the extracted indicators were divided into two categories with the pillars of need (with 10 sub-criteria) and competence (with 7 sub-criteria) each in two subgroups according to the nature of each indicator. Then, using fuzzy multi-criteria decision-making techniques, a decision-making hierarchy was created. The criteria in pairs in the form of a pairwise-comparison-survey were asked from 10 expert decision-makers in the fund. Finally, each criterion was weighted itself.

Findings: The results showed that in the countries studied, various criteria are considered according to the support policies of countries in granting the desired student facilities, but in a general and comprehensive view, these criteria can be categorized into two groups of need and competence. In Iran, according to the criteria devised in the Student Welfare Fund, the indicators of need are preferable in general comparisons with the indicators of competence, and in the sub-criteria of need in the order of special events that are subjected to the students. The student's health condition, the presence of dependents of students, were three indicators of importance.

Conclusion: Given the living condition of students and the importance of this segment of society in the sustainable development of the country, traditional methods of credit allocation based on the previous years do not have the necessary effectiveness and efficiency to provide scientific growth and increase in the level of student welfare that results in the scientific growth and development of the country. Therefore, the fuzzy multi-criteria decision-making method and the use of the indicators of need and competence devised in the research provides great coordination and flexibility in studentoriented credit allocation in terms of management and leads to improved justice in granting facilities.
\end{abstract}

Keywords: student facilities, ministry of health, fuzzy approach

Accepted: 3 Dec 2020

Copyright (c) 2020 by Author/s and Licensed by Veritas Publications. This is an open access article distributed under the Creative Commons Attribution 4.0 International (CC BY 4.0) which permits unrestricted use, distribution, and reproduction in any medium, provided the original work is properly cited. 
Determining the Optimal Method of Allocating Credits and Granting Facilities in the Student Welfare Fund ...

\section{INTRODUCTION}

Given the importance of higher education and its role in socio-economic development, it is the main pillar of governments' strategies. Therefore, managing financial resources that is to meet the educational and welfare needs of students as key elements of this sector is of great importance. Higher education has become increasingly important at the beginning of the 21st century. This level of education is considered in all countries, as the foundation of democratic civil societies, the engine of economic growth, and a political tool for the development of economic mobility of individuals and establishment of social justice [1]. Designing a reform framework for this system, perceptibly, requires the use of experiences and modeling of successful countries in this field. One of the key challenges in developing the quality of higher education systems is to ensure the conditions of students' access to educational services and material facilities required for education and full use of their potential [2,3]. Today, various organizations have been established in all parts of the world, part of whose task is to support students and susceptible and disadvantaged individuals. Iran is no exception. The Student Welfare Fund of the Ministry of Health, as an organization affiliated with the Ministry of Health and Medical Education, is working to provide services to the dear students of the Islamic Republic of Iran, doing the task to help improve the level of education of the community by granting student loans, marriage loans to students who get married while studying, housing deposit, and special help to students.

Student support in Iran is provided in the form of direct support. Direct support is given in various forms of loans, (housing) deposits, grants, scholarships, and special support grants such as student dormitories, shuttle services, and the like. In Iran, there is no indirect support such as family allowance and tax benefits for the students' families.

Therefore, to properly orient and optimally allocate the scarce financial resources and student facilities of the country to other applicant sectors, in this research a fuzzy multi-criteria decision-making method was used. So, while taking advantage of the opinions of experts and the involvement of the combined effect of several indicators in the final decision making, the problem of the existence of limitations ahead and the existing uncertainty in allocated resources and the budget will be considered. Using available information, the student support systems were studied in the developed countries and Iran.

The level of development of countries is one factor that can affect the financing structure of higher education, and in turn, is affected by the function of higher education systems. Therefore, while devising the indicators of the susceptible and unprivileged students and prioritizing these influencing factors in managers' decision making with a multi-criteria decision-making method based on fuzzy logic, this research intends to help the managers of student support funds, which are the only financial supporters of students in allocating and distributing student credits in the country, to optimally allocate their facilities and credits to applicants across the country. So, while working to devise and prioritize indicators and provide a complete and comprehensive definition of the underprivileged and susceptible student, besides achieving the goals of the fund, they have been able to fairly and intelligently distribute the limited resources of the fund among students by having the optimal and proper allocation with financial priority and susceptibleness. Quota and optimal allocation of the credits of the Ministry of Health and Medical Education to the different sectors of facilities (loans), as an appropriate monetary policy tool, can lead to directing credits to student groups which are more desirable for the managers of the Welfare Fund of the Ministry of Health as well as students. Therefore, this study seeks to identify and prioritize the optimal allocation of credits from the Student Welfare Fund of the Ministry of Health and Medical Education to different student groups to determine student facilities using a fuzzy multi-criteria decision-making model.

\section{METHOD}

The present study is descriptive-analytical in terms of purpose, functional in terms of results, quantitative in terms of the nature of the data, and research center and survey research in terms of data collection method, and also cross-sectional in terms of the perspective of the time horizon which compromises two phases, qualitative and quantitative. First, basic information is obtained using qualitative method and hypothesis is made, and then using quantitative methods to allocate funds optimally, the optimal facility portfolio is developed using analytical hierarchy process (fuzzy AHP). The statistical population, in the first place, includes the staff and student welfare affairs experts of the country's medical universities to devise influencing indicators in student welfare, and in the second place, 
Dhotre et al.

includes the expert staff managers of the Student Welfare Fund of the Ministry of Health to prioritize and weigh the identified indicators.

\section{The Qualitative Phase of the Study}

To identify facility payment indicators in selected countries which were studied, literature review and the websites of student support organizations in Austria, Australia, Estonia, Germany, USA, UK, Italy, Ireland, the Czech Republic, Denmark, Japan, France, Finland, Canada, Lithuania, Hungary, Norway, New Zealand were used. Also in the following, a comparative study of the criteria for payment of the facilities in Iranian support organizations such as the Student Welfare Fund of the Ministry of Health, the Foundation of Martyrs, Relief Foundation, Alavi Foundation, Elites Foundation, etc. has been discussed. Then, interviews with pundits (10 people) and experts (from the entire population of 200 people and a sample size of 132 people) involved in welfare affairs at the universities of medical sciences were conducted.

\section{FINDINGS}

To get familiar with the number of respondents to the questionnaire, pair-wise comparisons of the aspects such as gender, age, work experience, level of education, and the demographic characteristics of the respondents have been described $80 \%$ of whose were male and $20 \%$ were female. The highest frequency of respondents belonged to the age group of 30 to 40 and the lowest frequency of the respondents belonged to age over 50 , which make up only $20 \%$ of respondents.

Most respondents had work experience between 10 to 15 years and the lowest frequency of $20 \%$ belonged to work experience of over 15 years. $20 \%$ of the respondents had a master's degree and $80 \%$ had a Ph.D. degree.

\section{The Formation of Pair-wise Comparisons}

In this section, as an example, level 1 criteria and subcriteria are studied. First, pair-wise comparisons are made, and then they are completed by a fuzzy 1 to 9 range completed by 10 experts. They are then integrated using the geometric mean method, which is presented in Table 1-3.
Table 1. Pair-wise comparisons of the criteria

\begin{tabular}{ccc}
\hline & Competence & Need \\
\hline Competence & $(1,1,1)$ & $(0.199,0.253,0.357)$ \\
\hline Need & $(2.798,3.947,5.026)$ & $(1,1,1)$ \\
\hline
\end{tabular}

Table 2. Pair-wise comparisons of the sub-criteria of competence

\begin{tabular}{ccc}
\hline & Elected student & $\begin{array}{c}\text { Student eligible } \\
\text { for educational } \\
\text { and cultural } \\
\text { conditions }\end{array}$ \\
\hline Elected student & $(1,1,1)$ & $(0.357,0.458,0.577)$ \\
\hline $\begin{array}{c}\text { Student eligible for } \\
\text { educational and } \\
\text { cultural conditions }\end{array}$ & $(1.732,2.185,2.798)$ & $(1,1,1)$ \\
\hline
\end{tabular}

Table 3. Pair-wise comparisons of the sub-criteria of need

\begin{tabular}{ccc}
\hline & $\begin{array}{c}\text { Selected } \\
\text { culture and } \\
\text { sports students }\end{array}$ & $\begin{array}{c}\text { Selected } \\
\text { science } \\
\text { students }\end{array}$ \\
\hline $\begin{array}{c}\text { Selected culture and } \\
\text { sports students }\end{array}$ & $(1,1,1)$ & $(0.199,0.253,0.3$ \\
$57)$
\end{tabular}

\section{The Calculation of fuzzy and normal weights}

In this step, first, we compute the geometric mean of the fuzzy numbers of each row of the tables, and then we divide each geometric mean result by the sum of the geometric averages to get the fuzzy weight. Then, we de-fuzzify each fuzzy weight using Eq. $\frac{l+2 m+u}{4}$ and to normalize each non-fuzzy weight, it is enough to divide that weight by the sum of the non-fuzzy weights. For example, for the 'competence' criterion, the calculations are:

First, we calculate the geometric mean of the components of the rows, which is as follows.

The geometric mean of the first line

$$
\begin{aligned}
& =[(1,1,1) \times(0.199,0.253,0.357)]^{\frac{1}{2}} \\
& =(0.446,0.503,0.598)
\end{aligned}
$$

Similarly, these calculations are performed for the other lines, then, we get the sum of these geometric means, which is equal to $(2.119,2.49,2.84)$, then, the fuzzy weight of each criterion is equal to the geometric mean of that criterion divided by the sum of the geometric means. For example, for the 'competence' criteria, the fuzzy weight is: 
Determining the Optimal Method of Allocating Credits and Granting Facilities in the Student Welfare Fund ...

Table 4. Fuzzy and non-fuzzy weight of the major criteria

\begin{tabular}{ccccc}
\hline Criterion Name & $\begin{array}{c}\text { Geometric mean } \\
\left(\left(\prod_{j=1}^{n} \widetilde{\boldsymbol{P}}_{i j}\right)^{\mathbf{1} / n}\right)\end{array}$ & Fuzzy weight $(\widetilde{W})$ & $\begin{array}{c}\text { Non- } \\
\text { fuzzy } \\
\text { weight }\end{array}$ & Normal weight \\
\hline Competence & $(0.446,0.503,0.598)$ & $(0.157,0.202,0.282)$ & 0.211 & 0.206 \\
\hline Need & $(1.673,1.987,2.242)$ & $(0.589,0.798,1.058)$ & 0.811 & 0.794 \\
\hline$\sum\left(\prod_{j=1}^{n} \tilde{P}_{i j}\right)^{1 / n}$ & $(2.119,2.49,2.84)$ & & & \\
\hline
\end{tabular}

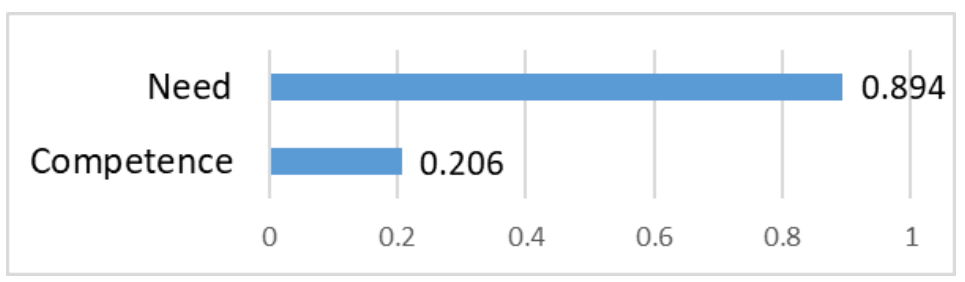

Figure 1. Weights of the major criteria

Table 5. Fuzzy and non-fuzzy weights of the sub-criteria of need

\begin{tabular}{cccccc}
\hline Criterion Name & $\begin{array}{c}\text { Geometric mean } \\
\left(\left(\prod_{j=1}^{n} \widetilde{\boldsymbol{P}}_{i j}\right)^{\mathbf{1} / \mathbf{n}}\right)\end{array}$ & Fuzzy weight $(\widetilde{W})$ & $\begin{array}{c}\text { Non-fuzzy } \\
\text { weight }\end{array}$ & $\begin{array}{c}\text { Normal } \\
\text { weight }\end{array}$ \\
\hline $\begin{array}{c}\text { Selected culture and sports } \\
\text { students }\end{array}$ & $(\mathbf{0 . 4 4 6 , 0 . 5 0 3 , 0 . 5 9 8 )}$ & $(0.157,0.202,0.282)$ & 0.211 & 0.206 \\
\hline Selected science students & $(1.673,1.987,2.242)$ & $(0.589,0.798,1.058)$ & 0.811 & 0.794 \\
\hline$\sum\left(\prod_{j=1}^{n} \tilde{P}_{i j}\right)^{1 / n}$ & $(2.119,2.49,2.84)$ & & & \\
\hline \\
\hline
\end{tabular}

Figure 2. Weights of the need criteria

$$
\begin{gathered}
\text { 'competence'fuzzy weight }=\frac{(0.446,0.503,0.598)}{(2.119,2.49,2.84)} \\
=(0.157,0.202,0.282)
\end{gathered}
$$

Also, similar operations are performed for all the criteria that fuzzy weights are given in the third column of the table. Then, to de-fuzzify each fuzzy weight, the following has to proceed.

'Competence' fuzzy weight $==(0.157,0.202,0.282)=$

$$
\begin{aligned}
& =>\text { 'Competence' non }- \text { fuzzy weight } \\
& =\frac{0.157+2 \times 0.202+0.282}{4}=0.211
\end{aligned}
$$

This process is also performed for all criteria, then, to normalize any non-fuzzy weight, we proceed:

$$
\begin{aligned}
{ }^{\prime} \text { Competence' Non } & - \text { fuzzy weight }=0.211= \\
& =>\text { 'Competence' normal weight } \\
& =\frac{0.211}{0.211+0.811}=0.206
\end{aligned}
$$

The need criterion with a weight of 0.894 is ranked first, and the competence criterion with a weight of 0.206 is ranked second. Similarly, for other pair-wise comparisons (sub-criteria) these calculations are performed as shown in Table 5 and Figure 2.

Among the competence sub-criteria, the eligible student for educational and cultural conditions with a weight of 0.687 is ranked first, and the elected student with a weight of 0.313 is ranked second. 
Among the sub-criteria of need, the selected science students with a weight of 0.794 have ranked first, and the selected students of culture and sports with a weight of 0.206 have ranked second. For the other 3 and 4 sub-criteria levels, pair-wise comparisons are performed similarly, then relative weights are calculated.

Higher education and its promotion have been considered by governments in all countries of the world and in different ways. By designing appropriate student support systems that commensurate with the internal conditions, the governments try to deliver a suitable platform for the scientific growth and development of students and the provision of skilled and expert human resources. One of the important factors in the success of a student support system is the ability of these systems to provide financial support fairly and in proportion to the actual needs of students.

As mentioned, students in different countries are mainly faced with three sorts of costs associated with education. These include education costs (mainly tuition fees), the cost of materials of teaching aids, and ultimately the costs of living expenses (including the cost of food, housing, transportation, and the like). The major question that arises, in this case, is from what sources should these costs be provided. In every country, the responsibility for financing higher education is distributed among three interest groups, including the student, his or her parents, the government, and the donors. The policy that governments adopt to meet these costs will determine the role of each interest group in financing higher education costs. In other words, government intervention in financing higher education is determined by considering the role of other interest groups. The policy that governments adopt to cover these costs determines the role of each interest group in financing higher education costs. In other words, the extent of government intervention in financing higher education is determined by the role of other interest groups.

Governments' intervention in the financing of higher education is done in different methods. Governments intervene in the higher education market in four methods. These four methods include regulations, allocation of subsidies, provision of government services, and transference of financial resources to students or their families. The first method of government intervention is mainly aimed to ensure access to educational services and the quality of these services. In the second method, the government guarantees students access to education and welfare services through the allocation of subsidies. In many

Table 6. The final weight of the factors

\begin{tabular}{|c|c|c|c|c|c|c|c|}
\hline Criterion & Weight & Sub-criteria 1 & Weight & Sub-criteria 2 & Weight & Sub-criteria 3 & Weight \\
\hline \multirow{24}{*}{$\begin{array}{l}\text { Competence } \\
\text { criteria }\end{array}$} & \multirow{24}{*}{0.206} & \multirow{5}{*}{ Elected student } & \multirow{5}{*}{0.313} & \multirow{2}{*}{$\begin{array}{l}\text { Selected culture } \\
\text { and sports students }\end{array}$} & \multirow{2}{*}{0.206} & National & 0.165 \\
\hline & & & & & & International & 0.835 \\
\hline & & & & \multirow{3}{*}{$\begin{array}{l}\text { Selected science } \\
\text { students }\end{array}$} & \multirow{3}{*}{0.794} & University & 0.059 \\
\hline & & & & & & National & 0.214 \\
\hline & & & & & & International & 0.727 \\
\hline & & \multirow{19}{*}{$\begin{array}{c}\text { Student with } \\
\text { educational and } \\
\text { cultural } \\
\text { qualifications }\end{array}$} & \multirow{4}{*}{\multicolumn{2}{|c|}{ Student status }} & 0.051 & - & - \\
\hline & & & & & \multirow{3}{*}{0.119} & Normal & 0.667 \\
\hline & & & & & & Transitional & 0.178 \\
\hline & & & & & & Guest & 0.155 \\
\hline & & & \multirow{15}{*}{0.687} & University of study & 0.3132 & - & - \\
\hline & & & & \multirow{6}{*}{ Field of Study } & \multirow{6}{*}{0.16} & Medicine, Dentistry, Pharmacy & 0.385 \\
\hline & & & & & & Basic medical sciences & 0.197 \\
\hline & & & & & & Health & 0.088 \\
\hline & & & & & & Nursing and Midwifery & 0.136 \\
\hline & & & & & & Nutrition and rehabilitation & 0.098 \\
\hline & & & & & & Paramedical & 0.12 \\
\hline & & & & \multirow{5}{*}{ Grade level } & \multirow{5}{*}{0.164} & Associate & 0.041 \\
\hline & & & & & & Discontinuous bachelor's & 0.62 \\
\hline & & & & & & Continuous bachelor's & 0.111 \\
\hline & & & & & & Master's & 0.231 \\
\hline & & & & & & Professional Doctorate, Ph.D. & 0.556 \\
\hline & & & & \multirow{3}{*}{ University of study } & \multirow{3}{*}{0.193} & Minimum grade point average & 0.073 \\
\hline & & & & & & 14-17 & 0.216 \\
\hline & & & & & & $17-20$ & 0.711 \\
\hline
\end{tabular}


Determining the Optimal Method of Allocating Credits and Granting Facilities in the Student Welfare Fund ...

Table 6 (continued). The final weight of the factors

\begin{tabular}{|c|c|c|c|c|c|c|c|}
\hline Criterion & Weight & $\begin{array}{c}\text { Sub- } \\
\text { criteria } 1\end{array}$ & Weight & Sub-criteria 2 & Weight & Sub-criteria 3 & Weight \\
\hline \multirow{40}{*}{$\begin{array}{l}\text { Need } \\
\text { Criteria }\end{array}$} & \multirow{40}{*}{0.794} & \multirow{21}{*}{ Student } & \multirow{21}{*}{0.811} & Student employment & 0.028 & - & - \\
\hline & & & & Student marital status & 0.066 & - & - \\
\hline & & & & $\begin{array}{c}\text { Number of dependents of } \\
\text { the student }\end{array}$ & 0.12 & - & - \\
\hline & & & & \multirow{3}{*}{ Student Residence } & \multirow{3}{*}{0.033} & Group 1 & 0.342 \\
\hline & & & & & & Group 2 & 0.338 \\
\hline & & & & & & Group 3 & 0.32 \\
\hline & & & & \multirow{3}{*}{ Student income } & \multirow{3}{*}{0.072} & Low (less than taxable income) & 0.587 \\
\hline & & & & & & Medium (2.75-6 million) & 0.328 \\
\hline & & & & & & High (6 million and up) & 0.086 \\
\hline & & & & \multirow{2}{*}{ Student residence status } & \multirow{2}{*}{0.05} & Rent & 0.852 \\
\hline & & & & & & Owner & 0.148 \\
\hline & & & & \multirow{3}{*}{ Student health status } & \multirow{3}{*}{0.204} & Healthy & 0.084 \\
\hline & & & & & & Disabled & 0.378 \\
\hline & & & & & & Patient & 0.538 \\
\hline & & & & \multirow{2}{*}{ Student special event } & \multirow{2}{*}{0.322} & Natural disasters & 0.456 \\
\hline & & & & & & Accident & 0.544 \\
\hline & & & & \multirow{4}{*}{ Student entrance quota } & \multirow{4}{*}{0.076} & District 1 & 0.082 \\
\hline & & & & & & District 2 & 0.17 \\
\hline & & & & & & District 3 & 0.333 \\
\hline & & & & & & Martyrs and Veterans & 0.415 \\
\hline & & & & $\begin{array}{l}\text { Student spouse } \\
\text { employment }\end{array}$ & 0.029 & - & - \\
\hline & & \multirow{19}{*}{$\begin{array}{l}\text { Student } \\
\text { family }\end{array}$} & \multirow{19}{*}{0.189} & \multirow{4}{*}{ Single-parent } & \multirow{4}{*}{0.045} & Manual laborer & 0.582 \\
\hline & & & & & & Employee & 0.188 \\
\hline & & & & & & Jobs that have work permits & 0.129 \\
\hline & & & & & & Freelance & 0.101 \\
\hline & & & & \multirow{4}{*}{ Two-parent } & \multirow{4}{*}{0.028} & Manual laborer & 0.575 \\
\hline & & & & & & Employee & 0.189 \\
\hline & & & & & & Jobs that have a work permit & 0.133 \\
\hline & & & & & & Freelance & 0.102 \\
\hline & & & & \multirow{2}{*}{$\begin{array}{l}\text { Number of fam3ily } \\
\text { members }\end{array}$} & \multirow{2}{*}{0.092} & Sparsely populated (Up to 4 people) & 0.154 \\
\hline & & & & & & Overpopulated (4 people or more) & 0.846 \\
\hline & & & & $\begin{array}{c}\text { Special event (natural } \\
\text { disasters) for the student } \\
\text { family }\end{array}$ & 0.341 & - & - \\
\hline & & & & $\begin{array}{c}\text { Family residence } \\
\text { (deprivation coefficient) }\end{array}$ & 0.124 & - & - \\
\hline & & & & \multirow{6}{*}{ Issues of the guardian } & & Death of the guardian & 0.212 \\
\hline & & & & & & Divorce & 0.052 \\
\hline & & & & & & Disability of the guardian & 0.225 \\
\hline & & & & & 0.291 & Illness of the guardian & 0.252 \\
\hline & & & & & & Household income & 0.089 \\
\hline & & & & & & $\begin{array}{l}\text { Imprisonment of a guardian or } \\
\text { breadwinner }\end{array}$ & 0.169 \\
\hline & & & & $\begin{array}{c}\text { Condition of residential } \\
\text { house }\end{array}$ & 0.078 & - & - \\
\hline
\end{tabular}

countries, providing specific support to students is done through this method. The third method of government intervention in higher education is the direct provision of educational and welfare services to students. In all the countries studied, including Iran, part of the educational and welfare services is provided directly by the government. The fourth method of government intervention in higher education of countries is in the form of transferring financial resources to students and their families. Different types of grants, allowances, and tax benefits in different countries are offered through this method. 
In this research, student support in some developed countries is also studied. The major part of these supports compromises direct support paid to the student. These supports come in the form of loans, grants, aids, scholarships, and tax benefits. The major part of the student support portfolios in different countries includes loans and grants (that include grants and scholarships). The combination of direct student support depends largely on the goals of the higher education system or the government in providing such support. In countries like Austria, England, and Ireland, for example, the major portion of direct support is in the form of grants. While in Australia, Japan, and New Zealand, all direct financial support is in the form of loans [4].

Another important issue is how to design student loan systems in different countries. Different components must be considered in the design of these systems. The first component in designing these systems is the criteria that must be considered for giving loans to individuals. The criteria are usually divided into two groups: need-based and competency-based. In Germany [5] (BAföG financial aid), the US (subsidized direct loans, non-subsidized direct loans, and Perkins federal loan program), Denmark [6], and Japan (second type loan program), student loans are paid only based on student's financial needs. In Australia, only meritbased criteria are considered for granting tuition loans for professional training courses abroad.

The second component that is considered in the design of student loan systems is the source of financing student loans. In many countries, such as Estonia, Australia, England, Norway, Denmark, Japan, Finland, Lithuania, New Zealand, and Hungary student loan resources are provided through the government budget [5].

The third component is the entity that provides loans. For example, in the US, England, Germany (KFW loan BAföG loan), Norway, Denmark, France, Lithuania, and New Zealand the provider of the loan is a government agency. However, in countries such as Japan, Finland, and France, loan resources are given to individuals by non-governmental independent institutions or banks $[5,7]$. Also, in Iran, the major part of student support is paid through the Student Welfare Fund of the Ministry of Science, Research and Technology, the Ministry of Health and Medical Education, and Azad universities.

The fourth component is if the student fails to repay the loan, who bears the ultimate risk of the loan. In
Japan, the student loan is from the government, but the risk of failure to repay is reduced by providing a guarantor by the student. In this country, students can provide a specific person or institution for the guarantee. In Estonia, Germany (KfW loan), Finland, and Hungary, where student loans are offered with a state guarantee, the government is responsible for the failure to repay loan installments [5]. Also, In Iran, the original amount of loan funds is paid by the Student Trust Fund or the Alavi Foundation, and the final risk of the loan is transferred to the student or guarantor of the loan through receipt of a valid notarized commitment document of the borrower and loan guarantees by the guarantor.

The fifth component is determining the amount of the loan for students and the expected amount of resources collected through repayment. As mentioned, determining the amount of loan should be done in a way that the student does not face financial problems after receiving the loan and financial support from parents. On the other hand, the amount of total debt should also be determined in such a way that the student does not face any problems in the payment of loan debt installments and does not have any arrears. Also, the criteria of student support organizations in Iran, by different sponsoring organizations are as Table 7.

By doing a comprehensive study about the criteria, over 50 criteria were observed as criteria used in similar national and foreign organizations. However, the way these indicators influence the allocation of facilities to the students was quite vague that in the Student Welfare Fund of the Ministry of Health, where we witnessed closely the events surrounding the allocation of facilities, only the priority in registration and introduction from the university was of importance. On the other hand, arbitrary choices were observed from the welfare experts at the college and university level who were in a way trustees of the fund. To this end, the fund decided to carry out its task which was devising guidelines for granting facilities and repayment and other welfare matters to students in a more concentrated form so that justice in granting financial facilities to students, not only among the students of a university but also among all universities across the country, from the most privileged to the most underprivileged areas of the country, would be established and credits should be allocated to them in the same way. Therefore, determining the credibility of the facilities, which was previously based on the history of the university, like the traditional budget in 
Table 7. Criteria for granting student facilities in Iran

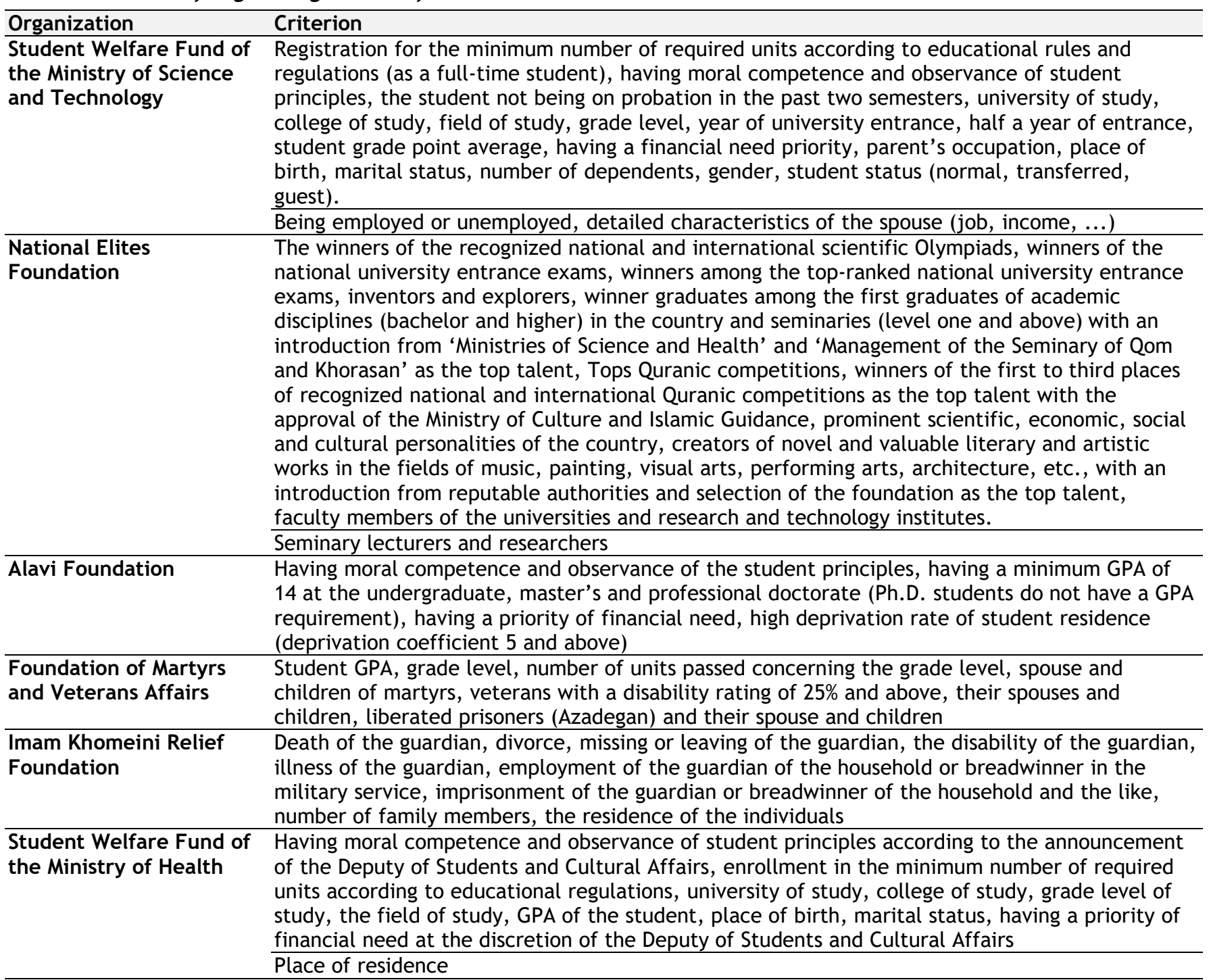

the country, to which an amount is added every year, turns to a credit allocation based on students with the priorities specified in this research in such a way that more credit would be allocated to each university that in a way have students with a higher priority so both vertical and horizontal justice is achieved in their genuine sense. The results of prioritizing the indicators based on the weight of each of them are presented in Table 7.

\section{CONCLUSION}

Student support can be considered a vital artery of higher education systems. Student support systems seek to provide access to higher education for students from all socio-economic backgrounds, which itself is one of the main pillars of sustainable development. In different countries, because of limited financial resources, providing these supports efficiently and effectively is of particular importance. Therefore, governments always try to improve the functioning of these systems by monitoring and evaluating their student support system and carrying out the reform process to ensure that everyone has access to higher education.

According to the results obtained from implementing the fuzzy hierarchical analysis process that weighed the indicators of need and competence, pundits and experts of the Student Welfare Fund of the Ministry of Health stated that need indicators with a weight of 0.794 are more preferable than competence indicators with a weight of 0.206 . Also, in the competence subset, 
criteria of the subset of the indicator of students with educational and cultural conditions weighing 0.687 compared to the elected student with a weight of 0.313 are more important for the material and spiritual support of the fund.

In the set of need indicators, the criteria that a student (0.811) has because of the individual needs of him or herself is more important than the criteria that a student is known as needy for his or her family conditions (0.189).

It should be noted that under the sub-category of the criteria of competence, an attempt was made to use criteria that represent the individual's susceptibility before implementing this plan. This consists of the set of indicators of the elected student, such as the national elected student and the winners of various scientific and sports Olympiads. On the other hand, it also includes a series of indicators that show the acquisition of competence during the implementation of the targeted plan, including the average student's GPA with three levels, the conditionality of an individual in three different sub-criteria, and the like which also shows the academic progress of the individual. If the Student Welfare Fund uses the results of this study, it will lead to the effectiveness and efficiency of this fund. Among the benefits that implementing this plan can bring to the Student Welfare Fund of the Ministry of Health the following can be mentioned: Improving the principles of university accreditation (conversion from university-oriented to student-oriented), direct and online monitoring of changes in the number of beneficiaries and the quality and quantity of receiving loans, preventing the use of personal tastes (university level experts) and ensuring the correct implementation of the instructions and monitoring justice for the benefit of all the students who are under the coverage, systematic and mechanized accountability of the fund in relation to upstream devices, making a platform for creating a software for granting automatic facilities, making a dynamic environment in granting facilities in the true sense and flexibility in the amount and the time of payment and repayment, making a suitable platform for paying loans to first-semester graduate students, paving the way for welfare card (making a lump sum payment of the loan amount of the total length of the study for better effectiveness in terms of credit card and the possibility of student use at the required condition and time), the flexibility of the payment ceiling of all types of loans for each person, reduction of the variety of facilities and creation of facilities with more effective amounts and in proportion to the current economic and social conditions.

Besides these available issues and problems in the livelihood and education of the students, in this study, we sought to create more transparency on the functions and powers of the Student Welfare Fund as much as possible that not only improves the performance of this fund but also in another category which can be considered as justice in the payment of facilities, not in the sense of equality, but another dimension that is also known as vertical justice, equality of students all over the country is in benefiting from the facilities of this fund.

Conflict of Interest: None to Declare

Source of funding: No funding

\section{REFERENCES}

1. Johnstone DB. Higher educational accessibility and financial viability: The role of student loans. Paper presented at the World Report on Higher Education: The Financing of Universities II International Barcelona Conference on Higher Education, Global University Network for Innovation (GUNI) Barcelona, Spain, 2005, May.

2. Education, Audiovisual and Culture Executive Agency. National Student Fee and Support Systems in European Higher Education-2015/16. 2015. Available at: http://eurydice.org.pl/wpcontent/uploads/2015/10/189EN.pdf

3. Ziderman, A. (2003). Student Loans in Thailand: Are they effective, equitable, sustainable? UNESCO Bangkok.

4. Meshkini M, KhorramRooz M, Ramezani Darh V, Azami S. Student Support in Developed Countries and Iran. Research Institute of Cultural and Social Studies, Ministry of Science, Research and Technology, 2016. Student Welfare Fund of the Ministry of Science, Research and Technology. (1395b). Food support basket for pregnant students. Retrieved May 10, 1.

5. European Funding Guide. Financing your studies in Italy 2014. Available at: http://www.europeanfunding-guide.eu/articles/fundingoverview/financing-your-studies-italy 
Determining the Optimal Method of Allocating Credits and Granting Facilities in the Student Welfare Fund ...

6. Forsknings ministeriet. State Educational Grant and Loan Scheme (SU) 2016. Available at: http://www.su.dk/english/state-educational-

7. Federal Student Aid. Income-Driven Plans 2016. Available at: https://studentaid.ed.gov/sa/repayloans/understand/plans/income-driven grant-and-loan-scheme-su/

166. European Funding Guide. Grants and Loans in Denmark 2014. Available at: http://www. european-funding-guide.eu/articles/grants-andloans/grants-and-loans-denmark

https: //www.ejbms.net 